\title{
Contemporary Currents in Japanese Machizukuri (Citizens Collaborative Community Improvements and Management) and Their Socio-Cultural Meanings*
}

\author{
Takashi Ariga \\ Department of Architecture, Faculty of Science and Engineering, Waseda University, Tokyo, Japan \\ Email: tariga@waseda.jp
}

\begin{abstract}
This paper studies the contemporary attempts of Japanese Machizukuri, Citizens Collaborative Community Improvement and Management, and their socio-cultural meanings in order to shed light on the sustainable planning approaches dealing with population ageing and decreasing. In recent years, as response measures for non-physical local issues such as environmental problems and welfare, and with the aim of further enhancing community-centred planning capabilities against a background of decentralisation in various fields and the establishment of civic society, new cooperative/collaborative-style planning theory is being deployed. Through this process, community improvement and management is becoming deeper, in terms of technology, systems, and technique. The study attempts to find out a solution to real-world problems-how to construct a comprehensive planning theory based on spatial and social challenges arising in modern civic communities, with local resources, social capital and systems that have resulted from such issues. It also seeks to show how to achieve a vision for the city as a whole by mutually compiling individual community improvement and management scenarios and programs, based on the autonomous determination and future vision of the organisations and residents that play leading roles in the community.
\end{abstract}

KEYWORDS Machizukuri, citizens collaborative community improvement and management, civic society, local resources, social capital and systems, interactive scenario making

Received July 24, 2017; accepted August 21, 2017.

\section{Outlook on Community Improvement and Management}

Community improvement and management is a dynamic process in which the organisations that make up a local community play a leading role, and which reflects the position of the various inhabitants and users over the course of time from past to future. The focus is on familiar living environments and everyday urban built environments. An ideal vision of the community to be shaped is defined by 'editing' the interrelationships between diverse spatial elements and social environments through a step-by-step process. A direction for the use of unique materials and resources to be synthesised is defined in order to realise the vision.

* This paper is a rewrite of 'Improvement and management of Community Management Theory', (Ariga 2010) with additional content included.
Community improvement and management focuses on the places and environments that are unique to the locality, the lifestyle and livelihoods there, and the qualities of history and culture passed down through the people of the area. Its activities result in the creation of spaces and physical environments. Future directions are found within the interrelationships between local elements, leading to the revival of places and the reconstruction of spatial environments through a systematic integration of multiple plan elements and resources in a general direction. Local traditional industries, unique townscapes and landscapes, places handed down for people to live in, and traditions preserved in local lifestyles all serve as elements of community improvement and management. These contextual and traditional value resources play a role in the plan to make the vision of the future a reality.

In recent urban and city-centre revitalisation projects, 
priority has been given to visible economic impacts and immediate results, so much so that there is a declining number of dynamic opportunities to formulate a future direction for society as a whole by interconnecting largescale mechanisms that assemble these kinds of converging local resources over time with community improvement and management activities in a variety of regions. To present a regional grand design, there needs to be a mechanism for planning the management of the regional environment-an aggregate of the natural environments, urban spaces, and socio-economic activities-through collaboration between local citizens and experts, as well as social technology that comprehensively integrates local resources and the underlying desires of citizens as planning information. In modern community improvement and management in our so-called 'era of civic society' with its diverse and increasingly complicated values, in which the creation of a sustainable environment, based on existing urban stocks, is required as a social proposition, more so than a preliminary determination of a future vision of environments and spaces to aim for, the key to success lies in planning mechanisms and information technologies that strategically guide the process of excellent community improvement and management by local people. For example, in the case of inner city revitalisation in old urban districts, it is often necessary to balance community preservation efforts to protect the livelihoods of residents based on space stocks and functions such as small and mediumsized factories, warehouses, and old apartments with urban attractions.

In this kind of community improvement and management, in addition to maintaining the quality of life of many elderly and socially marginalised people, it is also important to implement continuous 'plan management and promotion' efforts that involve renovating existing built environmentse.g., city blocks and buildings-in small space units, and to link these individual initiatives serially to achieve local revitalisation. That is, unlike large-scale revitalisation projects that establish the areas subject to plans and projects from the outset, deliberate orientation of the community improvement and management program is needed for serial application to the mutual revival of the entire space of the region and social environments, while responding individually to each and every community issue across the urban area. The community improvement and management focused on in this paper includes this concept.

In community improvement and management, the unique urban vision of the district is preserved by citizens and the local community, and 'community improvement and management as a process' that creates new value is indispensable. The importance of a new town planning method that realises spatial visualisation of the desired urban vision based on social systems and mechanisms and their common values, while serially implementing concrete projects and initiatives in a chain-like manner, has also been pointed out.

\section{Evolving Approaches to Community Improvement and Management and Social Background}

Community improvement and management theories and methodologies for urban spaces and physical environments in built-up areas are designed to be more universal, reflecting the achievements and knowledge gained through various practices. In particular, the theory of community improvement and management, despite being based on traditional disciplines such as architecture, civil engineering, and landscape design, can be said to have repeatedly fused and split off from other fields, leading to the formation of its own planning theories and methodologies in the process. In recent years, as response measures for non-physical local issues such as environmental problems and welfare, and with the aim of further enhancing region-centred planning capabilities against a background of decentralisation in various fields and the establishment of civic society, new cooperative/collaborative-style planning theory is being deployed. Through this process, community improvement and management is becoming deeper, in terms of technology, systems, and technique.

Allan B. Jacobs once posited that 'urban design is an arrangement of space and buildings which promotes the concepts of order/efficiency, beauty, sociability, and reflects cultural and sub-cultural trends and preferences' (Jacobs 1987). He also said that 'urban design is the process by which the needs of a community (people) are organised to construct an environment suitable for livability and cultural growth'. In the US and other foreign countries, the importance of collaborative activities by multiple agents has been pointed out-local organisations play a leading role and they cooperate with local governments and experts to renovate and improve nearby community environments and urban spaces. Also, in China, South Korea, Thailand, and other Asian countries, the word Machizukuri, community improvement and management, has already started to be used by researchers and experts interested in Japan's urban problems and its efforts to recover from large-scale natural disasters. 
Locally led planning and technology for community improvement and management has expanded and evolved, constantly adjusting its role and positioning and depending on the methods and procedures of legal urban planning. For example, it involves cooperating with legal initiatives aimed at urban infrastructure improvement and management, making proposals for private businesses led by rights holders or local organisations, or organising/ forming community improvement and management conferences or associations, and these efforts are applied to a wide range of mechanisms. In addition, with the spread of indirect support by intermediary organisations that network together urban planners and social investors, the role of the civic platform in a broad sense has continued to expand, for example through mutual collaboration between remote areas, and support for and participation in remote areas. Examples include the participation of willing citizens in the revival of vacant houses and abandoned land. The national government's direct support mechanism for the organisations responsible for community improvement and management is also helping to expand these efforts.

For example, the individual efforts of resident/landowners, seen in the conservation and revitalisation of traditional townhouses and warehouses, and the collaborative community improvement and management efforts by residents and local government aimed at preserving and revitalising townscapes and roadside buildings as integral streetscapes go beyond merely protecting traditional building assetsthey are significant as efforts to activate the untapped charm and vitality of the town, so to speak, to ensure that in any revitalisation the unique local culture and history is compatible with contemporary utilisation and value. In this kind of community improvement and management, efforts to incorporate private spaces such as buildings and gardens that are privately owned by residents and related rights holders into the social and public initiatives of community improvement and management, and to renovate such spaces to make them open to the public, serve as a major driving force, but inevitably the places and buildings where this can be done will be limited.

The Landscape Law and Historical Town Planning Law assume that local governments will cooperate with residents, landowners, citizens, etc., in creating original community improvement and management plans and related institutional methods, according to local circumstances. In light of this, it seems that in today's world it is necessary to prepare options for the social mechanisms for implementing community improvement and management, according to local conditions. Broadly speaking, there should be two options available. One is to continue following the framework used up to now, based on the minimum rules of 'regulation/control'; the other is for each district to draw up a detailed urban vision that is based on 'emergence/cocreation, with a shared clear direction for the future. There is also a need to ensure that each building and community improvement and management proposal expresses the local character, through individual discussion. Furthermore, each locality must be able to choose which course of action it wishes to take.

\section{Study of Modern Community Improvement and Management- The Approach of Architects and Urban Designers}

In debates surrounding future visions of cities in Japan, many architects present various concepts in terms of both planning and methods for urban design, through practical design and planning proposals.

Koh Kitayama has pointed out: 'In modern cities centred around economic activities, spaces are divided up according to market principles, and at the same time, people are divided and isolated. In modern societies, conflicts arise between the commons and market. This commons/ market conflict is a problem inherent to the world of humans, but in our "modern" civilisation, there is also the ontological principle of conquering nature-the tendency of opposing natural environments and creating artificial environments. Cities and buildings support our ordinary lives as artificial environments that cut off natural environments, within the norms of "modern" life.' (Kitayama $2017,1)$ Kitayama's argument is that for modern cities, it is necessary to create locally unique spaces, and places and environments that citizens can maintain, manage, and utilise communally, based on environmental resources, and also to build a social system to enable this.

In Japan, there used to be woodlands and fuel-wood forests known as satoyama. Many of these were planted by local communities and were maintained, managed, and utilised communally. The satoyama, in addition to being places for supplying charcoal, which at the time was indispensable for livelihoods and living, also served as joint work areas for local communities. Work activities that took place in these areas included thinning trees and cutting grass to keep the satoyama in sound condition. Thus, satoyama played a very important role as social common capital that formed through such joint work. Social common capital, which will need to be maintained and 
managed in the coming years through ongoing upgrades and improvements, exists in modern community improvement and management as well. An example of this is historical scenery and townscapes as local common assets that go beyond frameworks of space based on capitalist property rights that distinguish between 'public space' and 'private space'. Another example is settlements of living environments and urban landscapes, as districts formed as groups, transcending individual building site units.

With regard to such efforts for building and urban design affecting urban scenery and townscapes, Makoto Watanabe argues the following: 'Although the difficult problem of how to mediate the "in-between spaces" between new buildings and surrounding traditional buildings may already be resolved in Italy and other European countries, in Japan, the issue is being resolved through continuous trial and error.' (Watanabe 2016, 1)

As far as urban scenery and townscapes, as social common capital, are concerned, this is certainly an important issue.

\section{Case Study: Yokkaichi City, Mie Prefecture-Plan- ning Management and Systems for a 'Lifestyle Environment City' Created from District Improve- ment and Management}

Yokkaichi City is an industrial city located in the northern part of Mie Prefecture with a population of nearly 320,000. A naval fuel base was located in the city before World War II, and the city expanded along the coastline, its economy developing around a petrochemical complex and port (Figure 1). Throughout the era of high economic growth, substantial infrastructure was built (e.g., roads, drainage facilities, and parks), along with buildings financed by the private sector. On the other hand, since the city's industrial zone is concentrated along the eastern coast of the city, the rich natural environment on the western side of the city has been preserved, almost without any loss. The city faced various ups and downs in the course of its improvement and management, however. One example of this was the rapid decline of heavy and chemical industries. As the vitality of these industries declined, the city suffered various problems. For instance, the heart of the city was hollowed out and the outskirts of the city were degraded due to the abandonment of farmland and encroachment of satoyama by soil quarrying. On top of that, cleared land prepared for inland expansion to deal with an anticipated rise in urban density has not been fully utilised.

Given the demand for such community improvement and management scenarios for reviving the city and

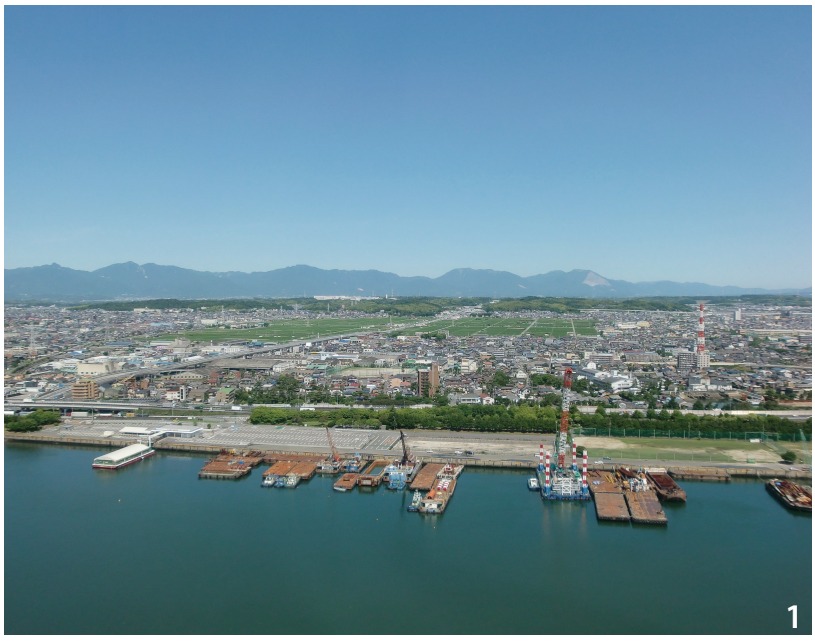

Figure 1 Vision of city that coexists with the natural environment (Source: "View to West from Port Building "Yokkaichi City Bulletin Section).

locality, Yokkaichi City formulated a grand design for its city planning master plan in July 2002. Under the plan, the city government will positively evaluate existing urban areas with mature infrastructure cultivated during the city's improvement and management phase, as well as the abundant natural environments and farmland in the suburbs, as existing stock. Then, in cooperation with citizens, they came up with ideas for utilising the natural stock to implement community improvement and management. Five districts have already proposed ideas to the city, and the municipal government has worked to create draft plans and engaged in local consultation, with the goal of formulating a vision for each area and district. As part of these efforts, Agata District, made up primarily of rural areasthe entire district is designated an urbanisation control zone-and Mie District, located on the outskirts of the urban city centre, included in their proposals a presentation of their unique community improvement and management problems as well as details of their attempts to resolve them.

The entire Agata District is designated an urbanisation control zone (Figure 2). One of the parts of the city with the highest agricultural production, it is also home to a mix of farming and non-farming households, with systematically developed housing projects within tracts of farmland. The community improvement and management concept of Agata district, with a future vision characterised by the slogan 'Agata, garden city in harmony with nature', includes 'the cultivation of relaxing places for residents through the creation of satoyama in Okayama' Okayama had once been a satoyama that was adored by the locals as a place for excursions, but it was later sold 


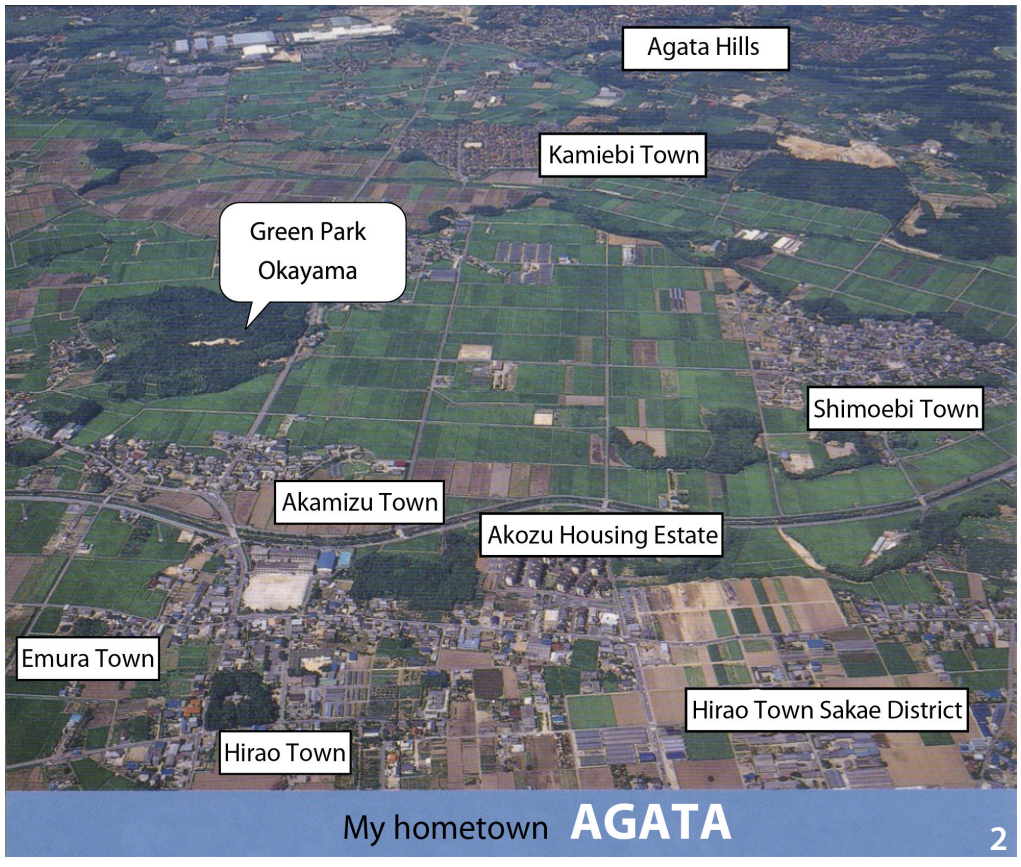

Figure 2 Agata, garden city in harmony with nature (Source: Green Park Okayama 5th Anniversary Commemorative Magazine). off in lots for holiday homes and then largely abandoned. The area has been neglected in recent years and people have been dumping waste in the area illegally. It was in this area that a residents group established the "We Love Green Park Okayama Association' (Agata District Machizukuri Committee 2009). So far, approximately 1.3 ha of the land has been turned into city parkland. Many local people participated in the preparation of the park, including elementary and junior high school students. Since the park's opening, a variety of events have been held in the park, such as nature study sessions and bamboo craft workshops. Most of the neglected satoyama is a result of lifestyle changes in rural areas; the land was abandoned after there was no longer a need to produce firewood and fertiliser. Therefore, if new joint management goals can be identified for this satoyama, I believe that ways to revive it can be discovered. Currently, although it is only used as a park, setting new goals for the satoyama in accordance with future community improvement and management plans could be an effective means for local management to achieve coexistence between a natural environment and social utilisation.

The efforts in Yokkaichi City are a good example of the implementation of a management planning system affecting the living environment urban planning of a whole city, originating with creative civic community improvement and management at the district level, devised from a system perspective. Particularly in district community improvement and management that enables coexistence with the natural environment and rural environment, local viewpoints are gradually being reflected in urban planning that covers a whole region, by means of communication between local government and local residents on the environmental revival and planning of the city as a whole, through community improvement and management planning at the district level.

\section{Interactive Scenario Making of Various Community Improvement and Management Programs and a Vision of the City}

The three visions below, representing more practical goals, are based on the above discussion on modern community improvement and management planning and methods.

1. Community improvement and management design as local public stock

Community improvement and management design is a local public asset. Excellent community improvement and management design enables the improvement and management of appealing urban areas and enhances their value as local stock. Such a design enhances local urban vitality, sustainability, and competitiveness, and also becomes an attractive asset for forming residential, commercial, and business districts. The use of such a design will lead to active investments and activities for the improvement and management of a better design, and it increases the environmental stock of the locality as a whole. This, in other words, can be described as an autonomous community improvement and management design that enhances 
the quality of urban spaces. In this process, the archetypes that serve as norms for dynamic urban spaces are latent.

2. Compilation of individual profit and community profit-redesign of planning system-urban design system/organisation for deploying individual community improvement and management design to visions of overall urban spaces and environmental quality

The quality of individual space renovations - that is, the performance of spaces and environments that local communities can conceive and share-needs to be evaluated according to an index, and the positioning viewpoints and design units need to be clearly specified in the plan for the city as a whole. It is important to lay out the viewpoints and methods for evaluating the vision and environmental quality performance of the Japanese city, which continues to constantly and dynamically change, and on this basis to try to reach consensus on environmental management. In the framework of this plan, there is a need to ensure consistency between the units for evaluating the environment and the community improvement and management planning units based on this design management.

3. Environmental performance of urban spaces and their evaluation, and improvement and management of design methods. Sharing of city visions and autonomy of individual space renovation-from urban design from the whole to the individual

In the dynamic, transformational process of cities, gradual, step-by-step space renovation of autonomous localities will slowly change the form and structure of the entire city. To ensure consistency within the city as whole for such renovations of autonomous local units, it is important to lay out the form and structure to be realised for the vision of the city as a whole and to share this widely throughout society. On top of this, it is vital to put a system in place for managing the effect of the overall vision of the city on individual space renovations and environmental improvements. Creating a system for managing urban environments with a collaborative community improvement and management design that focuses on the city as a whole as well as the individual spaces is essential.

\section{Conclusion}

What this paper attempts to is a trial-and-error effort to find a solution to real-world problems-how to construct a comprehensive planning theory based on spatial and social challenges arising in modern civic community improvement and management sites, with local resources, social capital and systems that have resulted from such challenges. It also seeks to show how to achieve a vision for the city as a whole by mutually compiling individual community improvement and management scenarios and programs, based on the autonomous determination and future vision of the organisations and residents that play leading roles in the community. There are many community improvement and management themes that residents and citizens consider as challenges, such as the community's unique history, natural environments, cultural and art elements, urban activities and functions, space recognition/psychology/behaviour, and architectural form/space type. Also, while in many cases these challenges are deeply connected to the history and context of the specific place, they are also closely interrelated with environments over a wider area, through urban activity, movement, and exchanges.

Although community improvement and management technology has deepened and developed in each field and domain, at the same time it seems to be getting more fragmented and segmented by theme. Apart from the benefits of specialisation, an effective planning theory would be needed for the kind community improvement and management challenges in which multiple, different themes and specialisations contribute in a cross-disciplinary and fusion-style way, e.g., safety and security in urban areas and urban sustainability, as evident in the problems facing many modern cities.

\section{References}

Ariga, Takashi. 2010. "Improvement and Management of Community Management Theory." Machizukuri (Quarterly) (29): 81-96.

Jacobs, Allan, B. 1980. Making City Planning Work. Chicago: The American Planning Association.

Kitayama, Koh. 2017. "Post-Western/Non-Western (PW/ NW) International Research Project."

Watanabe, Makoto. 2016. “About 'Sampling' and 'Assembly' and its Correlation with 'Group Memory"' In Proceeding of the Forum Japan/Italy: Design and Domain, Values of Cultural Difference. Torino: Politecnico di Torino/Istituto Italiano di Cultura. 